\title{
ANALYSIS OF RHEOLOGICAL PROPERTIES OF MR FLUID BASED ON VARIATION IN CONCENTRATION OF IRON PARTICLES
}

\author{
Vikram G. Kamble and Shreedhar Kolekar \\ Department of Mechanical Engineering, St Joseph Engineering College, Manglore-575028, India
}

Received 2014-10-21; Revised 2014-10-23; Accepted 2014-10-29

\begin{abstract}
The main aim of this study is to synthesize magneto-rheological fluid in laboratory using silicon oil as carrier oil and it is mixed with variation in concentration of iron particles of size around 4-9 $\mu \mathrm{m}$, fine lithium grease is used as surfactant. Prepared MR fluid is tested under plate and cone type rheometer for finding is rheological properties like shear stress, shear rate, shear viscosity, storage modulus and loss modulus.
\end{abstract}

Keywords: Rheological Fluid, Shear Viscosity, Shear Rate, Shear Stress, Yield Stress, Modulus

\section{INTRODUCTION}

Among all the smart materials magneto rheological fluids are important group. MR fluids are materials with rheological properties are in the proportion to the magnitude of the magnetic field applied and are immediately reversible (Garg and Anderson, 2000). Magneto Rheological fluids belong to the class of controllable fluids. The essential characteristics of MR Fluid is their ability to reversibly change from free flowing, linear viscous liquids to semi solids having controllable yield strength in milliseconds when exposed to magnetic field (Liu et al., 2011). This feature provides simple, quite, rapid response interface between electronic controls and mechanical systems. The initial discovery and development of MR Fluid can be credited to (Rabinow, 1948; 1951) at the US National Bureau of standards in the late 1940s. These fluids are suspension of micro sized, magnetisable particles in an appropriate carrier fluid. However, in the presence of an applied magnetic field, the iron particles acquire a dipole moment aligned with the external field which causes particles to form linear chains parallel to the field (De Gans et al., 1999; Chin et al., 1999; Kordonskii et al., 1999; Bica, 2006a; Bombard et al., 2007; Pu et al., 2006; Bossis et al., 2003) as shown in the Fig. 1.
The phenomenon can solidify the suspended iron particles and restrict the fluid movement. Consequently, yield strength is developed within the fluid. The degree of change is related to the magnitude of the applied magnetic field and can cover in only few milliseconds. A typical MR fluid consists of $20-40 \%$ by volume of relatively pure, soft iron particles (carbonyl iron particles) these particles are suspended in synthetic oil, mineral oil, water or glycol. A variety of proprietary additives similar to those found in commercial lubricants are commonly added to discourage gravitational settling and promote particle suspension (Bica, 2006b). The ultimate strength of a MR fluid depends on the square of the saturation magnetisation of the suspended particles. The key to strong the MR fluid is to choose a particle with a large saturation magnetisation (Billie et al., 1998; Carlson and Spencer, 1996). Typically, the diameter of the magnetisable particles is 3 to 5 microns. Functional MR fluids may be made with large particles; however particle suspension becomes increasingly more difficult as the size increases (Carlson and Spencer, 1996) smaller particles that are easier to suspend could be used, but the manufacture of such particles is difficult. Significantly smaller ferromagnetic particles are generally available as oxides, such as the pigments commonly found in magnetic recording media.

Corresponding Author: Vikram G. Kamble, Department of Mechanical Engineering, St Joseph Engineering College, Manglore-575028, India 

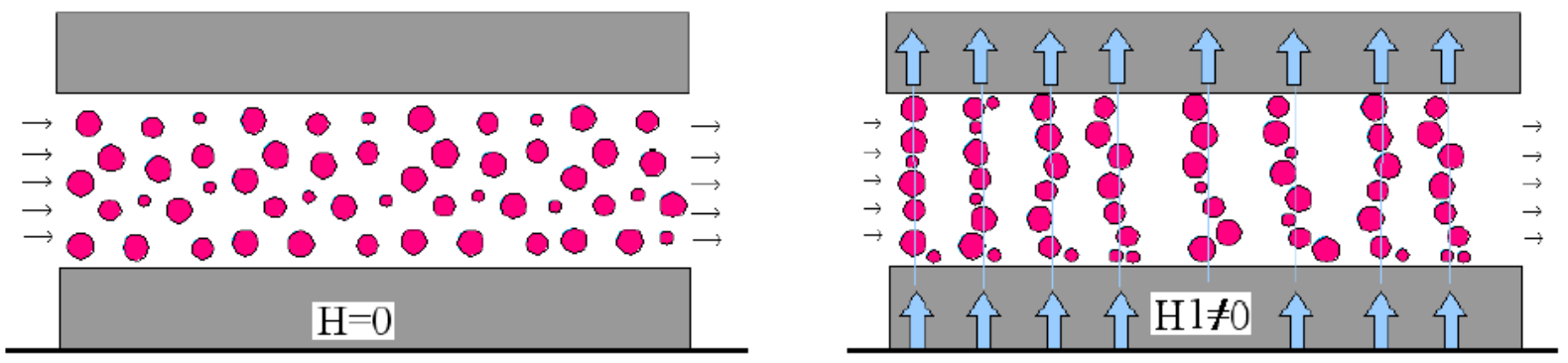

Fig. 1. Schematic representation of MR Effect

MR fluids made from such pigment particles are quite stable because the particles are typically only 30 nanometers in diameter. Magneto rheological materials can change their rheological properties under the influence of magnetic field (Kormann et al., 1996). The rheological properties can be changed whenever we needed rapidly, continuously and reversibly by changing the external magnetic field. This rheological behaviour is described by the magneto rheological effect.

\section{EXPERIMENT}

In this study the silicon oil is used is used (carrier oil) for magnetic carrier. The iron powder $\left(\rho=7.86 \mathrm{~g} \mathrm{~cm}^{-3}\right)$ with mean particle size of $4 \mu \mathrm{m}$ was used as magnetic particles and we used fine lithium grease to prevent the sedimentation or to prevent the settling of the iron particles and this fine lithium grease acts as the surfactant. Preparation of magneto-rheological fluid is explained in article (Kolekar, 2014). First, some amount of (18 wt\%) fine lithium grease is added to the carrier oil and then it is dissolved with the electric stirrer in room temperature. This stirring process is conducted around 4-5 $\mathrm{h}$ for complete mixing of carrier oil with surfactant. By this process the viscosity of the preparing MR fluid increases. After 4-5 h of stirring process iron powder $(25,30$ and 35 $w t \%)$ is poured in the same solution to give magnetic properties to it. Even this stirring process must be conducted for another 4-5 h. Finally the prepared solution will be of dark black in colour with tremendous increase in the viscosity of the fluid.

\subsection{Characterisation}

Study of Rheological properties of MR fluid is conducted using a plate and cone type rheometer for finding its properties like shear stress, shear rate, viscosity, storage modulus $\left(\mathrm{G}^{\mathrm{I}}\right)$ and loss modulus $\left(\mathrm{G}^{\mathrm{II}}\right)$.

\subsection{Specification of Rheometer}

- $\quad$ Plate and cone diameter $20 \mathrm{~mm}$ through to $60 \mathrm{~mm}$ as standard size range

- Rotational (shear) control-torque, speed and position

- Vertical (axial) control-gap and normal force

- Advanced vertical testing including squeeze flow and track testing

\subsection{Composition of Samples}

Preparation of MR fluid is prepared on the basis of percentage of weight as follows

$\begin{array}{llll}\text { Sample } & \text { Fe }(w t \%) & \begin{array}{l}\text { Silicon oil } \\ (w t \%)\end{array} & \begin{array}{l}\text { Grease } \\ (w t \%)\end{array} \\ \text { A } & 25 & 75 & 18 \\ \text { B } & 30 & 70 & 18 \\ \text { C } & 35 & 65 & 18\end{array}$

\section{RESULTS AND DISCUSSION}

The MR performance of all samples were conducted using plate and cone type rheometer, in this shear rate ranging from $0.01-100 \mathrm{~s}^{-1}$ and magnetic field strength ranging from $0-85 \mathrm{KA} / \mathrm{m}$. Figure $2 \mathbf{a}$ and $\mathbf{b}$ shows the flow characterisation of all three MR samples under no magnetic field applied. Here all three MR samples showed (Fig. 2a) typical particle suspension characteristics, in which the shear stress increases with increase in shear rate and Newtonian viscosity characteristics at a low shear and then shear thinning behaviour.

On the other hand (Fig. 2b) it is showing that the shear viscosity is fairly constant regardless of the shear rate (Choi et al., 1999). In this result we can see that the MR sample B has moderate shear stress and moderate shear viscosity when compared to the other two samples, based on the whole shear rate range. It indicates that the surfactant of MR fluid plays an important role. When 
external magnetic field was applied, all three samples exhibit Bingham fluid behaviour with yield stress, representing increase in the shear stress along with the shear rate (Pasquale et al., 2001). It can be seen that the shear stress and shear viscosity increased by magnetic field force. Whenever the magnetic field increases around the MR samples, the same shear stress becomes higher due to strong bond formation between the magnetic particles (iron particles). In this study, the test of all MR fluids begins from the rest state.

Figure 3 teaches us that the changes of shear viscosity with respect to the shear stress. The shear viscosity has the constant value at the high shear stress, whereas at low values of shear stress region the viscosity values are very high and shear viscosity abruptly decreased at the particular value of that shear stress which is well known as the static yield stress. In Fig. 4a and b Shows the amplitude sweep measurement in which it is explained about storage modulus $\left(\mathrm{G}^{\mathrm{I}}\right)$ and loss modulus $\left(\mathrm{G}^{\mathrm{II}}\right)$ with respect to the shear rate of the MR samples, in which the shear modulus and loss modulus are the result of viscous behaviour of the MR samples. Without applying the magnetic field the storage modulus and loss modulus are almost same like one another.

As we can observe the storage modulus is greater for some extent when compared to the loss modulus. Some researchers said in their work that the MR samples are very stronger when they are under magnetic field rather than without the magnetic field (Fang et al., 2009).

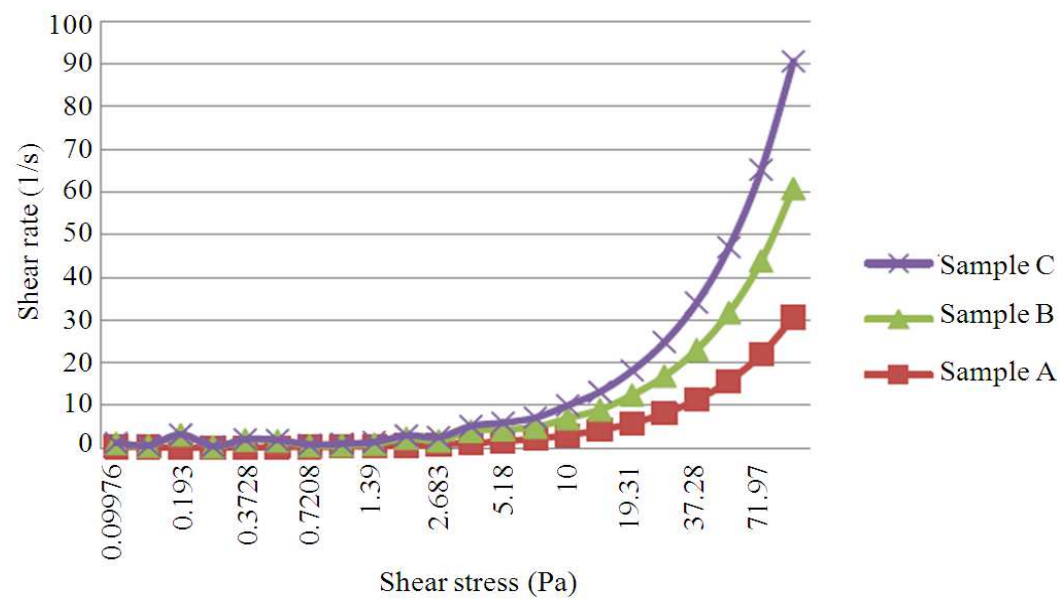

(a)

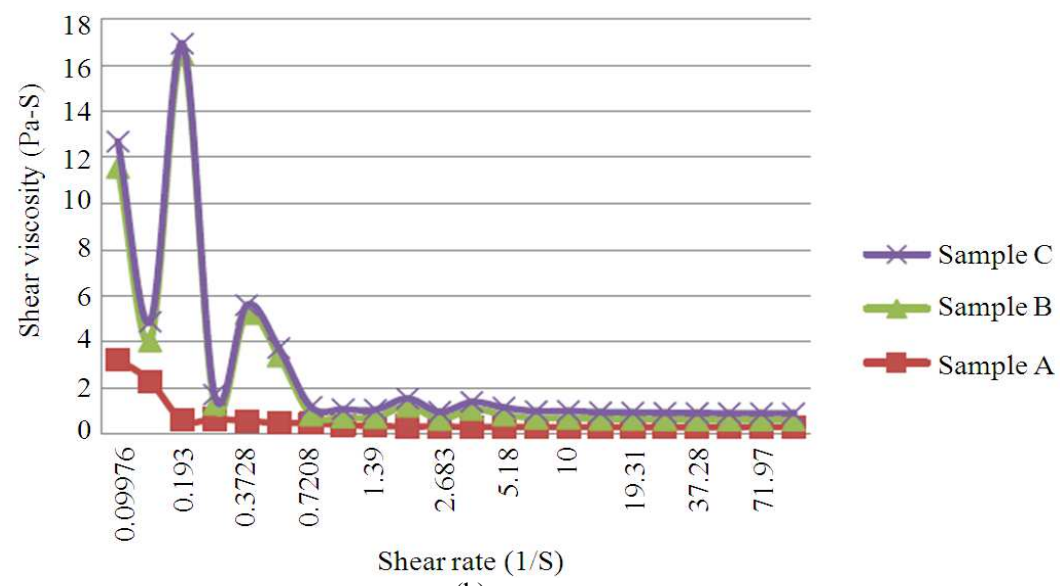

(b)

Fig. 2. (a) Shear rate as a function of Shear stress, (b) Shear velocity as function of Shear rate 
Vikram G. Kamble and Shreedhar Kolekar / American Journal of Nanotechnology 5 (2): 12-16, 2014

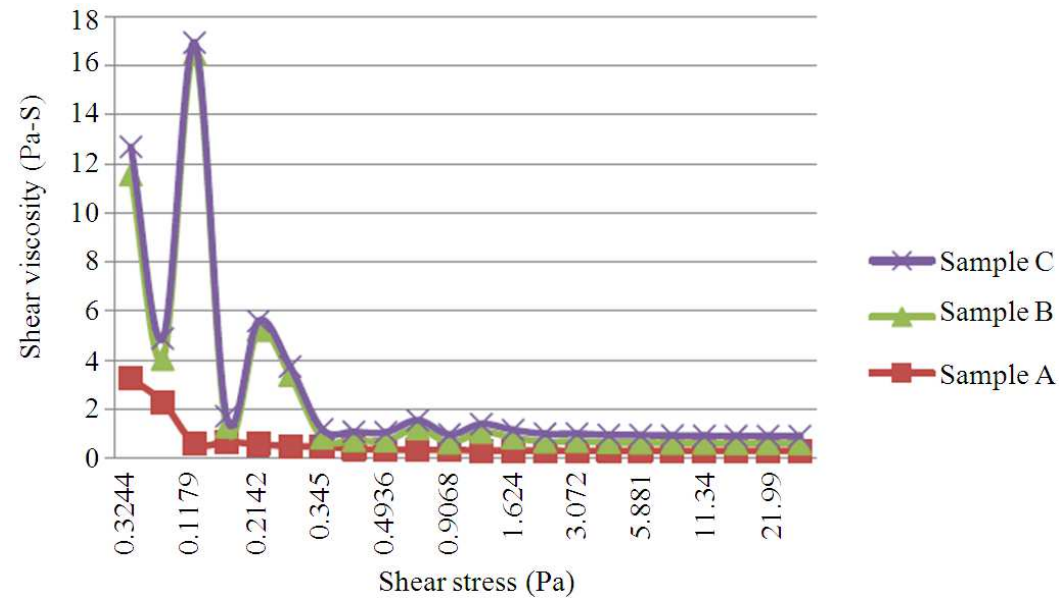

Fig. 3. Shear viscosity as a function of Shear stress
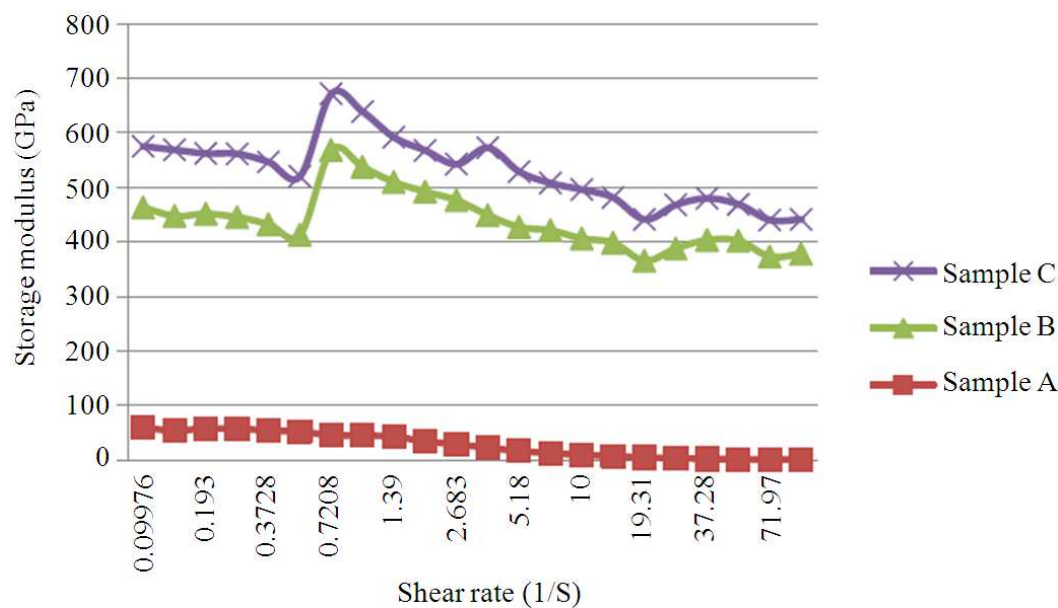

(a)

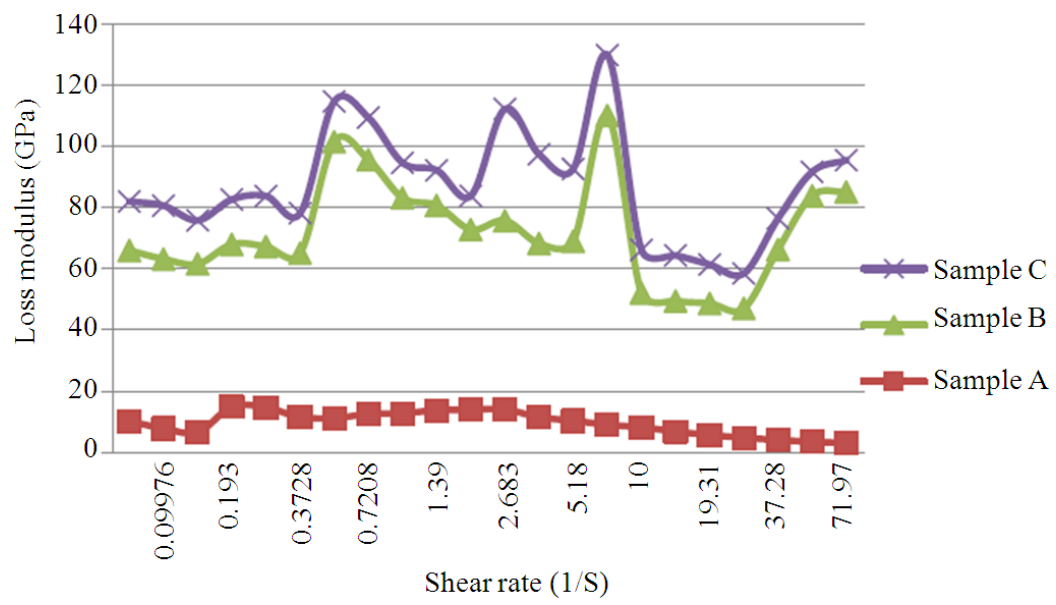

(b)

Fig. 4. (a) Storage modulus as a function of Shear rate, (b) loss modulus as a function of Shear rate 


\section{CONCLUSION}

Our MR samples are prepared by using magnetic particles and fine lithium grease along with the same carrier oil. The rheological properties like shear stress, shear rate, viscosity, storage modulus and loss modulus were studied and presented in this study. Moreover, it was found that the magneto rheological effect can be controlled by the particle alignment to the magnetic flux or field. It means that it is possible to obtain high magneto rheological effect by increasing the magnetic field. It can be seen that the shear stress is decreased when there is increase in the shear rate. The shear thinning behaviour is observed in shear viscosity data and magnetic sweep data.

\section{ACKNOWLEDGMENT}

We are gratefully acknowledge the support of the Malvern instruments New Delhi as they supported us in testing our samples and made our work successful.

\section{REFERENCES}

Bica, I., 2006a. Advances in magneto rheological suspension: Production and properties. J. Ind. Eng. Chem., 12: 501-515.

Bica, I., 2006b. Advances in magnetorheological suspension: Production and properties. J. Ind. Eng. Chem., 12: 501-515.

Billie, F.S., G. Yang, J.D. Carlson and M.K. Sain, 1998. "Smart" dampers for seismic protection of structures: A full-scale study. Proceedings of the Second World Conference on Structural Control, Jun.-Jul. 28-1, Kyoto, Japan, pp: 1-10.

Bombard, A.J.F., M. Knobel and M.R. Alcântara, 2007. Phosphate coating on the surface of carbonyl iron powder and its effect in magnetorheological suspensions. Int. J. Mod. Phys., B, 21: 4858-4867. DOI: 10.1142/S0217979207045761

Bossis, G., P. Khuzir, S. Lacis and O. Volkova, 2003. Yield behavior of magnetorheological suspensions. J. Magn. Mater., 258-259: 456-458. DOI: 10.1016/S0304-8853(02)01096-X

Chin, B.D., J.H. Park, M.H. Kwon and O.O. Park, 1999. Rheological properties and dispersion stability of Magnetorheological (MR) suspensions. Rheol. Acta, 40: 211-219. DOI: 10.1007/s003970000150

Choi, H.J., S.J. Vinay and M.S. Jhonb, 1999. Rheological properties of particle suspensions in a polymeric liquid. Polymer, 40: 2867-2872. DOI: $10.1016 / \mathrm{S} 0032-3861(98) 00498-4$
De Gans, B.J., C. Blom, A.P. Philipse and J. Mellema, 1999. Linear viscoelasticity of an inverse ferrofluid. Phys Rev E Stat Phys Plasmas Fluids Relat Interdiscip Topics., 4: 4518-4127. PMID: 11970308

Fang, F.F., H.J. Choi and M.S. Jhon, 2009. Magnetorheology of soft magnetic carbonyl iron suspension with single-walled carbon nanotube additive and its yield stress scaling function. Colloidal Surf. A: Physicochem. Eng. Aspects, 40: 46-51. DOI: 10.1016/j.colsurfa.2009.09.032

Garg, D.P. and G.L. Anderson, 2000. Research in active composite materials and structures: An overview. Proc. SPIE 3992, Smart Structures and Materials, 2: 12-12. DOI: $10.1117 / 12.388188$

Kolekar, S., 2014. Preparation of magnetorheological fluid and study on its rheological properties. Int. J. Nanosci., 13: 1450009-1450009. DOI: $10.1142 / \mathrm{S} 0219581 \mathrm{X} 14500094$

Kordonskii, V.I., S.A. Demchuk and V.A. Kuz'min, 1999. Viscoelastic properties of magnetorheological fluids. J. Eng. Phys. Thermophys., 72: 841-844. DOI: $10.1007 /$ BF02699403

Kormann, C., H.M. Laun and H.J. Richter, 1996. Mr fluids with nano-sized magnetic particles. Int. J. Mod. Phys. B, 10: 3167-3167.

DOI: $10.1142 / \mathrm{S} 0217979296001604$

Liu, Y.D., J.E. Kim and H.J. Choi, 2011. Core-shell structured monodisperse poly (3,4ethylenedioxythiophene)/poly(styrenesulfonic acid) coated polystyrene microspheres and their electrorheological response. Macromolecular Rapid Commun., 32: 881-886. DOI: $10.1002 / \operatorname{marc} .201100160$

Pasquale, M., C.P. Sasso, S. Besseghini and V. Chernenko, 2001. Field and temperature induced giant strain in single crystal Ni-Mn-Ga. IEEE Trans. Magn., 37: 2669-2671. DOI: 10.1109/20.951269

Pu, H.T., F.J. Jiang and Z.L. Yang, 2006. Preparation and properties of soft magnetic particles based on Fe3O4 and hollow polystyrene microsphere composite. Matter. Chem. Phys., 100: 10-14. DOI: $10.1016 /$ j.matchemphys.2005.11.032

Rabinow, J., 1948. The magnetic fluid clutch. Trans. Am. Institute Elect. Eng., 67: 1308-1315. DOI: 10.1109/T-AIEE.1948.5059821

Rabinow, J., 1951. Magnetic fluid torque and force transmitting device. United States Patent.

Carlson, J.D. and B.F.J. Spencer, 1996. Magnetorheological fluid dampers for semi-active seismic control. Proceedings of the 3rd International Conference on Motion and Vibration Control, (MVC' 96), pp: 35-40. 